\title{
3 Research Square

\section{Prevalence and Antimicrobial Susceptibility Pattern of Salmonella in Selected Export Abattoirs, East Shewa, Ethiopia}

\author{
Abayneh Alemu ( $\square$ abayalemu12@gmail.com ) \\ Ministry of Agriculture, Livestock Resource Sector
}

\section{Fikru Regassa}

Ministry of Agriculture, Livestock Resource Sector

\section{Nigatu Kebede}

Akililu Lemma Institute of Pathobiology, Addis Ababa University

\section{Rozina Ambachew}

St. Paul's Hospital Millennium Medical College

\section{Musse Girma}

Akililu Lemma Institute of Pathobiology, Addis Ababa University

\section{Wondewosen Tsegaye Sime}

St. Paul's Hospital Millennium Medical College

\section{Research Article}

Keywords: Abattoir, Antimicrobial susceptibility, Carcass, Prevalence, Salmonella, Salmonellosis

Posted Date: August 4th, 2021

DOI: https://doi.org/10.21203/rs.3.rs-753054/v1

License: (1) This work is licensed under a Creative Commons Attribution 4.0 International License. Read Full License 


\section{Abstract \\ Background}

Salmonella is one of the major causes of zoonotic foodborne pathogens in the world, with increasing concern for the emergence and spread of antimicrobial-resistant strains. In Ethiopia, the burden of Salmonella is still scarce in abattoirs.

\section{Objectives}

To determine the prevalence and antimicrobial susceptibility pattern of Salmonella in selected export abattoirs, East Shewa, Ethiopia.

\section{Methods}

A cross-sectional study was conducted from January 2020 to October 2020. A total of 345 samples were systematically included and out of which 150 carcass swabs (100 from goats and 50 from sheep carcass), 60 goat skin swabs, 60 knife swabs, and 75 human stool samples. The isolates were identified and characterized following standard bacteriological procedures and further confirmed by using Salmonella genus-specific primer by polymerase chain reaction. The isolates were subjected to antimicrobial susceptibility for 14 antibiotics using the Kirby-Bauer disk diffusion method. Data were entered and analyzed using STATA version 14. Fisher's exact test was used to assess significant differences among the abattoirs and type of samples. $P$-value $<0.05$ was considered as indicative of a statistical significance difference.

\section{Results}

Out of 345 total samples, 21(6.08\%) were positive for Salmonella. The specific prevalence of Salmonella in carcass, skin, and knife swabs were $10(6.67 \%), 7(11.67 \%)$, and $4(6.67 \%)$ respectively. There were no statistically significant differences in the occurrence of Salmonella among export abattoirs, and types of samples $(P>0.05)$. Salmonella was not isolated from sheep carcass and human stool samples. Among the 21 molecular confirmed Salmonella isolates, 7(33.3\%) were resistant to at least one antimicrobial agent and $2(9.04 \%)$ of isolates were resistant to two antibiotics, tetracycline, and streptomycin. All the isolates were $100 \%$ susceptible to kanamycin, chloramphenicol, cephalothin, gentamycin, and ceftriaxone.

\section{Conclusion}


Samples harbored Salmonella have significant public health impacts and hinder export performance. Thus, hygienic standards throughout the food chain process, surveillance systems, and one health approach are essential methods to minimize risks associated with the consumption of contaminated carcasses. Surveillance programs of antimicrobial usage in animals and animal products are important to ensure consumer safety.

\section{Introduction}

Salmonella is a foodborne pathogen that causes morbidity and mortality worldwide [1]. Non-typhoidal Salmonella enterica subsp. enterica is responsible for causing significant numbers of foodborne diseases in many countries [1]. Salmonella is a ubiquitous pathogen disseminated to different animals and environments [2, 3]. Food animals serve as the reservoir of non-typhoidal Salmonella (NTS) and pose a serious threat to public health and loss of production [4]. Globally, an estimated 93.8 million illnesses and 155,000 deaths are caused by Salmonella enterica annually [5]. Non-typhoidal Salmonella (NTS) species is one of the most important causes of foodborne disease and manifested by diarrhea, bacteremia, and focal suppurative infection [6]. The process of removing the gastrointestinal tract during the slaughtering of food animals is regarded as one of the most important sources of carcass and organ contamination with Salmonella at abattoirs $[7,8]$.

Salmonella contamination in the beef chain can occur at several stages along the food supply chain includes production, processing, distribution, retailing, preparing, and handling by consumers [9]. The prevalence of antimicrobial-resistance foodborne pathogen increased during recent decades, and it is a global concern [10]. Antimicrobial-resistance (AMR) is an international one health concern that adversely impacts both animal and human health [11]. The utilization of antimicrobial in agriculture for the growth promotion of animals and for the treatment of diseases caused by bacterial pathogens can lead to select antimicrobial-resistant pathogens [12].

In Ethiopia, different studies have been conducted to analyze the prevalence of Salmonella and antibiotics susceptibility profiles both in veterinary and public health setup $[13,14]$. However, there was a limited study on the magnitude and antimicrobial susceptibility profile of Salmonella in export abattoirs. This study was conducted to determine the magnitude and antimicrobial susceptibility profiles of Salmonella in selected export abattoirs in Ethiopia.

\section{Materials And Methods}

\subsection{Study areas and periods}

The study was conducted in three selected areas namely, Modjo, Bishoftu, and Dukem which are located in the East Shewa Zone of the Oromia region (Fig. 1). These areas were selected based on the availability of standardized carcass export abattoirs. The study was conducted from January to October 2020. 
In Ethiopia, export abattoirs were available in different sites of the country. Export abattoirs created good opportunities for the development of the economy through foreign currency earning. The certified export abattoirs are equipped with livestock reception pens, automatic, and semiautomatic mechanical slaughter processing chilling rooms, packaging equipment, and freezing facilities. The name of these export abattoirs are Luna, Organic, Halal, Abyssinia and Aljunia. Three abattoirs were selected from Modjo and one abattoir was selected from Bishoftu and Dukem.

\subsection{Study design}

A cross-sectional study design was conducted to determine the prevalence and antibiotic susceptibility pattern of Salmonella.

\subsection{Population}

\subsubsection{Source of population}

The study animals were apparently healthy young, male goats and sheep that were brought to abattoir for slaughter during the study in the period.

\subsubsection{Study population}

All apparently healthy young, male goats and sheep that were brought for slaughter, abattoir workers, and knives used for slaughtering were study populations that fulfilled the inclusion criteria.

\section{Eligibility criteria}

\section{Inclusion criteria}

- Male animals that were normal and ready for slaughtering purpose

- Carcass handlers working in selected export abattoirs and who are willing to participate in the study

\section{Exclusion criteria}

- Animals on antibiotic treatment for within two weeks at the time of sampling

- Carcass handlers with clinical symptoms and those are on antibiotic treatment within two weeks before the study

\section{Operational definitions}

\section{One health approach}

Is an approach that recognizes the health of people is closely connected to the health of animals and our shared environment.

\section{Multidrug-resistance}


It is resistant to three or more different classes of antibiotics.

\subsection{Sample size determination}

The sample size was calculated by using the single population proportion estimation formula given by Thrusfield and Christely [15], with a 95\% confidence level and 5\% desired precision. The sample size was calculated based on $5.7 \%$ and $3.57 \%$ expected prevalence of bovine and ovine samples respectively in Addis Ababa Abattoir Enterprise, Ethiopia [2].

$$
\mathrm{N}=\mathrm{Z}^{2 *} \operatorname{Pexp}(1-\mathrm{P})
$$

The sample size was calculated as:

$d^{2}$

Where: $\mathrm{N}$ = required sample size, $\mathrm{Z}$ = standard normal deviation (1.96) at 95\% confidence level

P exp = expected prevalence

$\mathrm{d}=$ desired absolute solution (0.05)

Accordingly, the calculated sample size was 150 taking into account a $10 \%$ non-response rate. A total of 345 samples (100 from goats and 50 from sheep = 150 carcass swabs, 60 goats skin swabs and 60 knife swabs, and 75 human stool samples) were collected for detection of Salmonella. Human stool samples were collected from five export abattoirs and from each export abattoir, 15 stool samples were collected.

\subsection{Sampling techniques}

To recruit the study participants, a systemic random sampling method was used to enroll eligible study participants. The numbers of study participants to be enrolled from each selected export abattoir were determined by proportionality (based on animal and human study participant load).

\subsection{Data collection procedure}

Sociodemographic characteristics: For the human sample, after taking written consent from each study participant, a semi-structured questionnaire was used to collect sociodemographic characteristics.

\subsection{Sample collection and transportation}

Study sites were visited to facilitate research collaboration before sample collection. Subsequently, a support letter requesting cooperation was sent to each study site, and the study was conducted from January 2020 to October 2020. The sampling days were randomly assigned to each abattoir. A minimum of 15 samples that contain carcass, skin, and knives swabs and human stool samples were collected from each abattoir.

\section{Carcass swabs}


Samples were collected from the carcass ( $n=150,100$ from goats, and 50 from sheep). Each carcass was sampled from four regions; neck, abdomen, thorax, and breast regions. Sampling areas delineated by sterile aluminum foil templates $(10 \times 10 \mathrm{~cm})$ resulting from a total area of $400 \mathrm{~cm}^{2}$. A sterile cotton-tipped swab $(2 \times 3 \mathrm{~cm}$ ) was first soaked in $9 \mathrm{ml}$ buffered peptone water (BPW) (Oxoid, England) and rubbed over the delineated area horizontally and vertically [2]. Two sterile cotton-tipped swabs were used to collect four consecutive areas.

\section{Skin swabs}

Samples were collected from external goats' skin surfaces $(n=60)$. Four areas were selected to collect the skin swabs. These are the abdomen, thorax, neck, and breast areas. A sterile aluminum foil template $(10 \times 10 \mathrm{~cm})$ resulting total area of $400 \mathrm{~cm}^{2}$ placed these regions. A sterile cotton-tipped swab with wooden shaft first soaked in $9 \mathrm{ml}$ of sterile buffered peptone water (BPW) (Oxoid, England) and rubbed over delineated area horizontally and vertically [9]. Two sterile cotton-tipped swabs were used to collect four consecutive areas.

\section{Knives swabs}

Samples from the knives $(n=60)$ were collected aseptically using sterile cotton swabs. It was collected by rubbing both sides of the knives using a pre-soaked swab [11].

\section{Stool samples}

After proper instruction, each study participant was informed to bring freshly voided stool in a clean, dry, and leak-proof disposable stool cup, and a total of 75 stool specimens were collected

Upon completion of all swabbing processes, the wooden shaft was broken off; and the cotton swab was left inside the test tubes contains $9 \mathrm{ml}$ of sterilized buffer peptone water (BPW) (Oxoid, England). The swab samples within test tubes were shaken for 30 seconds for the uniform distribution of microorganisms before transportation. Then samples were transported to Aklilu Lemma Institute of Pathobiology (ALIPB) medical microbiology laboratory in an icebox within 3-4 hours.

\subsection{Microbiological analysis}

Isolation and identification ofSalmonella: Isolation and identification of Salmonella were performed at Aklilu Lemma Institute of Pathobiology department of the medical microbiology laboratory. Salmonella isolation and identification were carried out in line with guidelines of the International Organization for Standardization (ISO 6579-1: 2017) and World Health Organization (WHO) global foodborne infections network laboratory protocol $[8,16]$.

\section{Preenrichment in non-selective liquid medium}

The swab samples were put in $9 \mathrm{ml}$ of buffered peptone water (BPW), (Oxoid, England). This pre-enriched sample incubated for $18-24$ hours at $37^{\circ} \mathrm{C}$ for recovery and proliferation of cell might be injured during 
processing or to make a number of the target organism grow to detectable level [4].

\section{Enrichment selective liquid media}

Enrichment selective broth namely, Rappaport Vassiliadis soya broth (RVS) (Oxoid, England CM950500G) for all samples except stool and selenite F broth for a stool sample (Oxoid, England, CM651-500G) were used to inhibit non-targeted microorganisms like gram-positive bacteria and coliforms and permit rapid multiplication of Salmonella. After pre-enrichment in buffered peptone water (BPW) $0.1 \mathrm{ml}$ cultures were transferred aseptically into $10 \mathrm{ml}$ of RVs and incubated for $18-24$ hours at $41.5^{\circ} \mathrm{C}$. For the stool sample, $0.1 \mathrm{ml}$ of culture from BPW was transferred to $10 \mathrm{ml}$ of selenite $\mathrm{F}$ broth, homogenized, and incubated for $18-24$ hours at $41.5^{\circ} \mathrm{C}$ and $37^{\circ} \mathrm{C}$ [4].

\section{Plating out and identification}

A loopful of $100 \mu \mathrm{m}$ was taken from RVs and selenite $\mathrm{F}$ broth and streaked into the xylose lysine deoxycholate agar (XLD) (Oxoid, England CM0469-500G) plates and incubated at $37^{\circ} \mathrm{C}$ for $18-24$ hours. Suspected Salmonella isolates were subcultured on the nutrient agar (Oxoid, England, CM0003-500G) and incubated at $37^{\circ} \mathrm{C}$ for $18-24$ hours. The isolates from the sub-culture were stored in the refrigerator at $4^{\circ} \mathrm{C}$ for the biochemical test, molecular testing, and antimicrobial susceptibility test [10].

\subsection{Biochemical characterization}

Suspected Salmonella colonies from nutrient agar (Oxoid, England CM0003-500G) were picked up and determined its biochemical characteristics using triple sugar iron agar (TSI) (Oxoid, England CM277500G), lysine iron agar (LIA) (Oxoid, England CM0381-500G), Simmon's citrate agar (Himedia, India CM0129-500G), urea slant (Himedia, India M111A-500G) and sulfide indole motility (SIM) (Oxoid, England S12-500G) agar [12].

\section{Molecular techniques}

Polymerase chain reaction (PCR) was used to confirm the identification made by phenotypic tests.

DNA extraction: Bacterial colonies confirmed as Salmonella by biochemical tests were cultured overnight on xylose lysine deoxycholate agar (XLD agar). Then DNA extraction was performed using the boiling method. The set of primer targeted conserved regions of Salmonella forward and reverse were used [8].

Table 1: Primers used to detect Salmonella 


\begin{tabular}{|lll|}
\hline Genome & Primers & Sequences $\left(\mathbf{5}^{\prime} \mathbf{3}^{\prime} \mathbf{)}\right.$ \\
\hline $\begin{array}{l}\text { Histidine transport } \\
\text { operon gene }\end{array}$ & Forward & ACTGGCGTTATCCCTTTCTCTGGTA \\
& & \\
& Reverse & ATGTTGTCCTGCCCCTGGTAAGAGA \\
\hline
\end{tabular}

Molecular confirmation by using polymerase chain reaction: All isolates shown specific biochemical characteristics of Salmonella was further confirmed by using genus-specific PCR as described by (29). It is based on the amplification of a 496-bp segment of histidine transport operon gene, which is highly conserved among species of Salmonella. Reference strain of S. Typhimurium (ATCC 14028) was used as a positive control during PCR. Polymerase chain reaction (PCR) amplification was run in reaction mixtures $(20 \mu \mathrm{l})$ with master mix $(10 \mu \mathrm{l})$, forward $(0.50 \mu \mathrm{l})$ and reverse $(0.50 \mu \mathrm{l})$ primer, nuclease-free water $(8.0 \mu \mathrm{l})$ and DNA template $(1.0 \mu \mathrm{l})$. Amplification was performed in a thermocycler with temperature profiles of 2 minutes at $94^{\circ} \mathrm{C}$ for initial denaturation followed by 35 cycles of at $94^{\circ} \mathrm{C}$ for 1 minute, annealing at $58{ }^{\circ} \mathrm{C}$ for 1 minute and extension at $72{ }^{\circ} \mathrm{C}$ for 1 minute with final extension step at $72{ }^{\circ} \mathrm{C}$ for 5 minutes [7].

Agarose gel electrophoresis and visualization of PCR products: Polymerase chain reaction (PCR) products were electrophoresed using 2 grams agarose powder (Rugby, UK) in $100 \mathrm{ml}$ of 1× TAE buffer (Bio Concept, Switzerland). A volume of $2 \mu$ of ethidium bromide was added to the gel before pouring it into the casting tray. A 100-bp DNA ladder was used as a molecular size marker to estimate the size of the products. A band of 496 base pairs (bp) was considered positive for Salmonella. Gel electrophoresis was carried out at 120 volts for 60 minutes, viewed under an ultraviolet (UV) transilluminator [5].

\subsection{Antimicrobial susceptibility test}

The isolates confirmed by polymerase chain reaction (PCR) were subjected to antibiotic susceptibility test using Kirby-Bauer disk diffusion techniques [17], on Mueller-Hinton agar (Oxoid, England) in following Clinical and Laboratory Standard Institute (CLSI, 2018) [18]. From each PCR confirmed isolate, three to four colonies grown on nutrient agar were transferred to a tube containing $3 \mathrm{ml}$ of nutrient broth (Oxoid, England). The broth culture was incubated at $37^{\circ} \mathrm{C}$ for $18-24$ hours and until its turbidity adjusted to 0.5 McFarland standards. The suspension was inoculated onto Mueller-Hinton agar (MHA) plates using sterile cotton swabs. The plates were uniformly inoculated by rubbing against the entire agar surface and rotating the plates at about 90 degrees three times.

The plates were held at room temperature for 15 minutes to allow drying. Antibiotic impregnated disks were applied to the surface of the inoculated plate using sterile forceps and incubated aerobically at $37^{\circ} \mathrm{C}$ 
for 24 hours. Salmonella isolates were tested for antibiotics includes kanamycin $(30 \mu \mathrm{g}, \mathrm{K})$, ciprofloxacin $(5 \mu \mathrm{g}, \mathrm{CIP})$, chloramphenicol $(30 \mu \mathrm{g}, \mathrm{C})$, cephalothin $(30 \mu \mathrm{g}, \mathrm{CEP})$, tetracycline $(30 \mu \mathrm{g}, \mathrm{TE})$, ampicillin $(10 \mu \mathrm{g}$, AMP), nalidixic acid $(30 \mu \mathrm{g}, \mathrm{NA})$, streptomycin $(10 \mu \mathrm{g}, \mathrm{S})$, gentamicin $(10 \mu \mathrm{g}, \mathrm{GEN})$, ceftriaxone $(30 \mu \mathrm{g}, \mathrm{CRO})$, amikacin $(10 \mu \mathrm{g}, \mathrm{AN})$, neomycin $(30 \mu \mathrm{g}, \mathrm{N})$, amoxicillin +clavulanic acid $(20 / 10 \mu \mathrm{g}, \mathrm{AMC})$ and sulfamethoxazolettrimethoprim(1.25/23.75 $\mathrm{g}$, SXT). Following the incubation of the plates at $37^{\circ} \mathrm{C}$ for 24 hours, a diameter of inhibition zone was measured to the nearest millimeters using a digital caliper and interpreted as sensitive (S), intermediate (I), or resistant (R) accordance with Clinical and Laboratory Standard Institute (CLSI, 2018) [18].

\section{Results}

\section{Sociodemographic characteristics of human study participants in selected export abattoirs}

A total of 75 carcass handlers were enrolled in this study with a response rate of $100 \%$. The sex distributions were 55 males and 20 females with an age range of 22-50 years old with a mean age of 32 years $( \pm 8.61 \mathrm{SD})$. Educational backgrounds were $3(5 \%)$ primary school, $65(86.6 \%)$ secondary school and $7(9.33 \%)$ have diploma certificate. Most of the respondents were married 50(67\%). All participants were trained about food hygiene and wearing personnel protective equipment. Among carcass handlers, $65(86.6 \%)$ have a certificate in food safety. All participants undertake periodical medical check-ups and wash their hands with soap and water after the toilet and touching any material (Table 2). 
Table 2

Socio-demographic characteristics of human study participants in selected export abattoirs, East Shewa, Ethiopia from January to October 2020

\begin{tabular}{|c|c|c|c|}
\hline Variables & Category & $\begin{array}{l}\text { Frequency } \\
(\mathrm{N}=75)\end{array}$ & $\begin{array}{l}\text { Percentages } \\
\text { (\%) }\end{array}$ \\
\hline \multirow[t]{2}{*}{ Age } & $22-35$ & 25 & 33.0 \\
\hline & $36-50$ & 50 & 67.0 \\
\hline \multirow[t]{2}{*}{ Sex } & Male & 55 & 73.3 \\
\hline & Female & 20 & 26.6 \\
\hline \multirow[t]{2}{*}{ Marital status } & Married & 50 & 67.0 \\
\hline & Single & 25 & 33.0 \\
\hline \multirow[t]{3}{*}{ Education } & Primary & 3 & 4.0 \\
\hline & Secondary & 65 & 86.6 \\
\hline & Diploma & 7 & 9.3 \\
\hline \multirow[t]{3}{*}{ Residency } & Modjo & 45 & 70.0 \\
\hline & Bishoftu & 15 & 15.0 \\
\hline & Dukem & 15 & 15.0 \\
\hline Having certificate of & Yes & 65 & 86.6 \\
\hline Food safety & No & 10 & 13.4 \\
\hline \multirow[t]{2}{*}{ Periodical medical check-up } & Yes & 75 & 100 \\
\hline & No & - & - \\
\hline \multirow[t]{2}{*}{ Consumption of raw meat } & Yes & 1 & 5.0 \\
\hline & No & 74 & 95 \\
\hline \multirow[t]{2}{*}{ Food hygiene training } & Yes & 75 & 100 \\
\hline & No & - & - \\
\hline \multirow[t]{2}{*}{ Using personnel protective equipments } & Yes & 75 & 100 \\
\hline & No & - & - \\
\hline \multirow[t]{2}{*}{ Workexperience years } & $5-8$ & 62 & 85.0 \\
\hline & $>9$ & 13 & 15.0 \\
\hline \multirow{2}{*}{$\begin{array}{l}\text { Hand washing by soap and water after toilet and } \\
\text { touching any materials }\end{array}$} & Yes & 75 & 100 \\
\hline & No & - & - \\
\hline
\end{tabular}




\subsection{Prevalence of Salmonella}

During the study period, a total of 345 samples were collected from five export abattoirs. Thirty-six of them shown suspected Salmonella colonies on xylose lysine deoxycholate agar (XLD) observed and only 21 isolates shown typical biochemical properties of Salmonella. These $21(6.08 \%)$ isolates were further confirmed by polymerase chain reaction (PCR) amplification and were confirmed as Salmonella (Figs. 2 and 3). Salmonella was not isolated from all human stool (75) and sheep carcass swabs (50). The highest proportion of positive samples were detected from goat skin swabs $7(11.67 \%)$ followed by goat carcass swabs $10(6.67 \%)$ and knife swabs $4(6.67 \%)$ (Table 3$)$.

Table 3

Prevalence of Salmonella on types of study samples in selected export abattoirs, East Shewa, Ethiopia from January to October 2020

\begin{tabular}{|llllll|}
\hline Sample types & No. of samples & No. of positives & $(95 \%$ Cl $)$ & Exact test & p-value \\
\hline Goat carcass swabs & 100 & 10 & $(3.5,11.19)$ & & \\
\hline Knife swabs & 60 & 4 & $(2.5,16.64)$ & & \\
\hline Goat skin swabs & 60 & 7 & $(5.7,23)$ & & \\
\hline Human stool samples & 75 & 0 & & 0.304 & 0.188 \\
\hline Sheep carcass swabs & 50 & 0 & & & \\
\hline Total & 345 & 21 & $(4.9 .11 .2)$ & & \\
\hline
\end{tabular}

PCR result by pi-chart

The 21 of the isolates were confirmed by polymerase chain reaction (PCR) test (Fig. 3).

\subsection{Antimicrobial susceptibility test of Salmonella isolates}

Among the 21 molecular confirmed Salmonella isolates, all the isolates were $100 \%$ susceptible to kanamycin, chloramphenicol, cephalothin, gentamicin, and ceftriaxone. A total of 21(95.2\%) and $1(4.76 \%)$ were intermediately resistant to neomycin and streptomycin, respectively (Table 4).

Table 4: Antibiotic susceptibility profiles of Salmonella isolates $(n=21)$ in selected export abattoirs, East Shewa, Ethiopia

Antimicrobials Antibiotic susceptibility profiles 


\begin{tabular}{|c|c|c|c|c|}
\hline & & S (\%) & I (\%) & R (\%) \\
\hline & $30 \mu \mathrm{g}$ & $21(100 \%)$ & $0(0 \%)$ & $0(0)$ \\
\hline & $5 \mu \mathrm{g}$ & $20(95.2 \%)$ & $0(0 \%)$ & 1(4.76\%) \\
\hline & $30 \mu \mathrm{g}$ & $21(100 \%)$ & $0(0 \%)$ & $0(0 \%)$ \\
\hline & $30 \mu \mathrm{g}$ & $21(100 \%)$ & $0(0 \%)$ & $0(0 \%)$ \\
\hline & $30 \mu \mathrm{g}$ & $19(90.47 \%)$ & $0(0 \%)$ & $2(9.52 \%)$ \\
\hline & $10 \mu \mathrm{g}$ & $20(95 \%)$ & $0(0 \%)$ & $1(4.76 \%)$ \\
\hline & $30 \mu \mathrm{g}$ & $20(95 \%)$ & $0(0 \%)$ & 1(4.76\%) \\
\hline & $10 \mu \mathrm{g}$ & $18(85 \%)$ & $1(4.76 \%)$ & $2(9.52 \%)$ \\
\hline & $10 \mu \mathrm{g}$ & $21(100 \%)$ & $0(0 \%)$ & $0(0 \%)$ \\
\hline & $30 \mu \mathrm{g}$ & $21(100 \%)$ & $0(0 \%)$ & $0(0 \%)$ \\
\hline & $10 \mu \mathrm{g}$ & $20(95.2 \%)$ & $0(0 \%)$ & 1(4.76\%) \\
\hline & $10 \mu \mathrm{g}$ & $0(0 \%)$ & $20(95.2 \%)$ & 1(4.76\%) \\
\hline icid & $20 / 10 \mu \mathrm{g}$ & $20(95.2 \%)$ & $0(0 \%)$ & 1(4.76\%) \\
\hline ethoprim & $1.25 / 23.75 \mu \mathrm{g}$ & $20(95.2 \%)$ & $0(0 \%)$ & $1(4.76 \%)$ \\
\hline
\end{tabular}

S=susceptible I=intermediate $\mathrm{R}=$ resistant

Overall, $7(33.33 \%)$ of the isolates were resistant to at least one of the tested 14 antimicrobial agents. Among of the 21 isolates, only $2(9.04 \%)$ isolates were resistant to tetracycline and streptomycin (Table 5). 
Table 5

Drug-resisitance pattern in selected export abattoirs from January to October 2020

\begin{tabular}{llll} 
Number of drugs & Antibiotics & No. of resistant Isolates & Isolate origion \\
\hline One drug & CIP, AM, NA, AN, N, AMP and SXT & $7(33.33 \%)$ & CS \\
Two drug & TE (2) and S(2) & $2(9.04 \%)$ & SW
\end{tabular}

Key: $\mathrm{CIP}=$ Ciprofloxacin, $\mathrm{AM}=$ Ampicillin, $\mathrm{NA}=$ Nalidic Acid, $\mathrm{AN}=$ Amikacin $\mathrm{N}=$ Neomycine $\mathrm{AMP}=$ Amoxacillin + Clavulanic acid, $S X T=$ Sulfamethoxazole + Trimethoprim, $T E=$ Tetracycline, $S=$ Streptomycin, CS = Carcass Swab, S = Skin Swab

\section{Discussion}

In this study, the overall prevalence of Salmonella was $21(6.08 \%)$. This is comparable with finding in dairy cattle in central Ethiopia (7\%) [19], Colorado State University veterinary teaching hospital (5.9\%) [20], and on pork and goat carcass in the Bahamas (5.9\%) [21]. On the contrary, our finding is lower than study reported on exotic chickens in Debre Zeit and Modjo, Ethiopia (14.6\%) [22], ground beef at retail store in Jalisco State, Mexico (56.7\%) [23], from milk and meat in Bangladesh (60\%) [24], Kwata slaughterhouse Awka, Anambra State (33.5\%) [16] from abattoir and environment in Nigeria (92.31\%) [25] and raw beef in Wolaita Sodo municipal abattoir, Southern Ethiopia (12.5\%) [26]. However, the result is higher than study conducted on slaughtered cattle in Addis Ababa, Ethiopia (3.7\%) [3], slaughter sheep in Turkey (0.7\%) [27], food handlers at the University of Gondar, Ethiopia (3.1\%) [28], from animal-origin food items in Gondar, Ethiopia (5.5\%) [29] and slaughtered bovine, and ovine in Addis Ababa abattoir enterprise 4.64\% [2]. Salmonella was not detected from sheep carcass swabs, which is comparable with the study conducted on slaughter sheep carcass swabs in Turkey [30].

The discrepancies in Ethiopia as well as in other countries could be associated with the degree of exposure of animals to stress factors like transportation and starvation, climatic conditions, management practices, age groups, species of animals, hygienic conditions, types of abattoirs and facilities, food handling and geographical difference. In addition, the discrepancies in isolation might be depending on the difference in sampling strategies, study periods, sample size, study population, methodologies, and culture media.

In the present study, the proportion of Salmonella in different samples such as skin swabs $(11.66 \%)$, carcass swabs $(6.66 \%)$, and knives swabs $(6.66 \%)$. The findings show that prevalence in this study is lower than the study conducted to the isolation of Salmonella in carcass swabs (30\%), and skin swabs (59.7\%) of cattle slaughtered in South Africa [4] and knives swabs (16.7\%) selected dairy farms, abattoir, and humans at Asella Town, Ethiopia [9]. However, it is higher than study conducted (1.8\%) on carcass swabs on animal sources in South Africa [31], (2.5\%) knife swabs from the abattoir, and environment in Nigeria [32], and (1.6\%) skin swabs of dairy cattle slaughter in Northern Italy [33], and (4.5\%) Kwata slaughterhouse, Awka, Anambra State [16]. The difference could be associated with hygienic status, management systems, and cross-contamination among materials used in slaughtering procedures. 
Animals that entered into abattoirs were particularly dirty, which contributed to the spread and crosscontamination of skin with Salmonella pathogen. The proportion of the carcass contamination in this study recorded, and the potential source of contamination is diverse. The carcass could have been contaminated during skin removal or evisceration. In the abattoirs, the same knife was used for the slaughtering of the different animals, and some individuals ignored the adequate sterilization of the knives and this might be contributing to chances of carcass contamination. Occasionally, when moving the carcass from one place to another place; there is close contact between the different carcass and this may result in the carcass-to-carcass transfer of Salmonella. All these factors may also contribute to the prevalence of Salmonella in selected export abattoirs, East Shewa, Ethiopia.

In the present study, we have also assessed the antimicrobial susceptibility test of Salmonella isolates. The result of the in-vitro antibiotics sensitivity test to Salmonella isolates showed different degrees of sensitivity against the tested antibiotics ranging from $0-100 \%$. The highest susceptibility $(100 \%)$ was observed against kanamycin, chloramphenicol, cephalothin, gentamycin, and ceftriaxone. The isolates were susceptible to ceftriaxone and chloramphenicol, which is in agreement with the previous finding of cattle slaughtered in Addis Abeba [3] and dairy cattle in central Ethiopia [19]. In addition, the isolates in the current study were susceptible to gentamycin and ceftriaxone, which is in line with similar studies from food handlers at the University of Gondar, Ethiopia [28].

Among the 21 molecular confirmed Salmonella isolates, 7(33.3\%) were resistant to at least one antimicrobial agent and 2(9.04\%) of Salmonella isolates were resistant to tetracycline and streptomycin. This is in conformity with the study conducted in Ecuador that reported resistance rate for other antibiotics ranged from $11.1 \%$ up to $33.3 \%$ [34]. Multidrug-resistance has not been recorded in this study. In this study, among tested antibiotics, kanamycin, ceftriaxone, chloramphenicol cephalothin, and gentamicin were found to be the most effective drugs to inhibit the in vitro growth of these isolates. Thus, these drugs could be used for empirical treatment in the area where a culture facility is not available.

\section{Limitation of the study}

In this study, isolates were not serotyped and molecularly characterized due to budget constraints.

\section{Conclusion And Recommendations}

The prevalence of Salmonella in selected export abattoirs was found to be $21(6.08 \%)$. This may indicate that it has public health impacts and leads to a socio-economic problem. Thus, bacteriological assessment of Salmonella pathogen from export abattoirs was essential to improve surveillance system and hygienic standards. Among the tested antimicrobial: kanamycin, ceftriaxone, chloramphenicol, cephalothin, and gentamicin were $100 \%$. Antimicrobial treatment approaches should be based on the bacteriological culture followed by an antimicrobial susceptibility test.

\section{Abbreviations}


ALIPB: Aklilu Lemma Institute of Pathobiology; AMR: Antimicrobial-Resistance; AST: Antimicrobial Susceptibility Testing; BPW: Buffered Peptone Water; CLSI: Clinical and Laboratory Standards Institute; MoA: Ministry of Agriculture; PCR: Polymerase Chain Reaction; RVS: Rappaport Vassiliadis Soya Broth; SPHMMC: Saint Paul's Hospital Millennium Medical College; WHO: World Health Organization; XLD: Xylose Lysine Deoxycholate

\section{Declarations}

Acknowledgments: This study was financially supported by the Ministry of Agriculture, Livestock Resource Sector, Akililu Lemma Institute of Pathobiology, Addis Ababa University, and St. Paul's Hospital Millennium Medical College. The authors are deeply grateful to the participants of the research.

Disclosure: This research did not receive any specific grant from funding agencies in the public, commercial, or not-for-profit sectors.

Ethical consideration: Ethical approval was obtained from St. Paul's Hospital Millennium Medical College (SPHMMC) (Pm23/423) Institutional Review Board (IRB). A letter was written from St. Paul's Hospital Millennium Medical College Department of Microbiology, Immunology, and Parasitology to the research study area. In addition, official permission was also obtained from the Ministry of Agriculture (MoA), abattoir inspection, and certification directorate to undertake the study. Study participants were informed about the purpose and procedures of the study. Written informed consent was obtained from each human study participant. To ensure confidentiality, participants' data were linked to the code number.

Availability of data and materials: The data sets used and analyzed in the study are available from the corresponding author on reasonable request.

Consent for publication: Not applicable

Competing interests: The authors declare that they have no competing interests.

Authors' contributions $\llbracket A A, F R, N K, R A$, and WTS participated in the conception of the study, drafting, and reviewing the manuscript. AA was involved in sample collection and laboratory investigation. AA and NK have participated in laboratory sample processing. AA and GM were involved in the polymerase chain reaction (PCR). All authors read and approved the final manuscript.

\section{Authors' information}

1, 2* Ministry of Agriculture, Livestock Resource Sector, P. O. Box 62347, Addis Abeba, Ethiopia

${ }^{1}$ St. Paul's Hospital Millennium Medical College, P.O Box 1271, Addis Ababa, Ethiopia

${ }^{3}$ Akililu Lemma Institute of Pathobiology, Addis Ababa University, P.O Box 1176, Addis Ababa, Ethiopia 


\section{References}

1. Madoroba E, Kapeta D and Gelaw A. K (2014) Salmonella serovars and antimicrobial-resistance profiles of cattle slaughtered in South Africa. J. Vet. Res., 83(1): 1-8.

2. Kebede A, Kemal J, Alemayehu H and Mariam S. H (2016) Isolation, identification and antibiotic susceptibility of Salmonella from slaughtered bovines and ovines in Addis Ababa abattoir enterprise, Ethiopia: Cross-sectional study. Int. J. Bacteriol., 3(10): 1-8.

3. Ketema L, Ketema Z, Kiflu B, Alemayehu H, Terefe Y, Ibrahim M et al., (2018) Prevalence and antimicrobial susceptibility profiles of Salmonella serovars isolated from slaughtered cattle in Addis Ababa, Ethiopia. Biomed Res. Int., 34(10): 1-7.

4. Lu Z, Mitchell R, Smith R, Karn J, Kessel J, Wolfgang D et al., (2013) Invasion and transmission of Salmonella Kentucky in adult dairy herd. BMC Vet. Res., 9(245): 1-8.

5. Habing G. G, Manning S, Bolin C, Cui Y, Rudrik J, Dietrich S et al., (2015) Within-farm changes in dairy farm-associated Salmonella subtypes and comparison to human clinical isolates in Michigan, 2000-2001 and 2009. Appl. Environ. Microbiol., 81(17): 5724-5735.

6. Arguello H, Álvarez-Ordoñez A, Carvajal A, Rubio P and Prieto M (2013) Role of slaughtering in Salmonella spreading and control in pork production. J. Food Prot., 76(5): 899-911.

7. Foley S. L, Johnson T. J, Ricke S. C, Nayak R and Danzeisen J (2013) Salmonella pathogenicity and host adaptation in chicken-associated serovars. Microbiol. Mol. Biol. Rev., 77(4): 582-607.

8. Mikoleit M. L (2014) Microbiology of food chain horizontal method for detection, enumeration and serotyping of Salmonella: Detection of Salmonella (ISO 6579-1). Enteric Dis. Lab. Branch Centers Dis. Control Prev., 5(1): 1-45.

9. Ainslie-Garcia M. H, Farzan A, Newman J. E and Lillie B. N (2018) Salmonella fecal shedding in pigs rom birth to market and its association with the presence of Salmonella in palatine tonsils and submandibular lymph nodes at slaughter Can. J. Vet. Res., 82(4): 249-255.

10. Eguale T, Birungi J, Asrat D, Njahira M. N, Njuguna J, Gebreyes G et al., (2017) Genetic markers associated with resistance beta-lactam and antimicrobials in non-typhoidal Salmonella isolates from humans and animals in central Ethiopia. Antimicrob. Resist. Infect. Control., 6(13): 1-10.

11. Abdus S. M, Momen S, Sarker R, Taufiqur R, Lutful S. M, Tanvir R. M et al., (2019) Antibiotic-resistant Escherichia coli and Salmonella spp. associated with dairy cattle and farm environment having public health significance. Vet. World., 12(7): 984-991.

12. Mendonca E. P, De Melo R. T, Nalevaiko J and Monteiro G. P (2019) Spread of serotypes and antimicrobial-resistance strains of Salmonella spp. isolated from broiler. Brazilian J. Microbiol., 50(10): 515-522.

13. Addis Z, Kebede N, Sisay Z, Alemayehu H, Yirsaw A Kassa T et al., (2011) Prevalence and antimicrobial-resistance of Salmonella isolated from lactating cows and contact humans in dairy farms of Addis Ababa: Cross sectional study. BMC Infect. Dis., 11(222): 1-19. 
14. Tesfaye W, Melese A, Henok S and Yohanis M (2016) Prevalence and antimicrobial susceptibility profile of Salmonella species from ready to eat foods from catering establishments in Jigjiga City, Ethiopia. African J. Microbiol. Res., 10(37): 1555-1560.

15. Thrusfield M and Christley R (2018) Veterinary epidemiology. 4th ed. Veterinary clinical sciences royal school of veterinary studies University of Edinburgh and Epidemiology and population health institute of infection and global health and institute of veterinary science University of Liverpool 1864.

16. Campos E and Rica C (2015) World Health Organization (WHO) global foodborne infections network laboratory protocol. WHO GFN Lab. Protoc., 5(33): 1-43.

17. Hudzicki J (2016) Kirby-Bauer disk diffusion susceptibility test protocol. Am. Soc. Microbiol., I(8): 123.

18. Performance standard for antimicrobial susceptibility testing (2018). 28th ed. Clinical and Laboratory Standards Institute (CLSI) supplement M100 38(32): 1-60.

19. Eguale T, Engidawork E, Gebreyes W. A Asrat D, Alemayehu H, Medhin G et al., (2016) Fecal prevalence, serotype distribution and antimicrobial-resistance of Salmonella in dairy cattle in central Ethiopia. BMC Microbiol., 16(20): 1-11.

20. Burgess B. A and Morley P. S (2019) Risk factors for shedding of Salmonella enterica among hospitalized large animals over 10 years period in veterinary teaching hospital, Colorado State University. J. Vet. Intern. Med., 10(33): 2239-2248.

21. Hanlon K. H, Echeverry A, Miller M. F and Brashears M. M (2018) Establishment of preliminary baseline of Salmonella presence on pork and goat carcasses harvested in the Bahamas to address food and nutritional security interventions. Am. Soc. Anim. Sci., 8(4): 1-7.

22. Asfaw D, Tadesse B and Ebabu A (2020) Prevalence and antibiotic-resistance patterns of Salmonella isolated from caecal contents of exotic chicken in Debre zeit and Modjo, Ethiopia. Int. J. Microbiol., 6(10): 1-6.

23. Gonzalez D, Barba J, Pacheco C, Julia A, Carlos A, Garcia S et al., (2018) Frequency and antimicrobial-resistance of Salmonella serotypes on beef carcasses at small abattoirs in Jalisco State, Mexico. Food Prot., 75(5): 867-873.

24. Rahman M. A and Rahman A. K (2016) Detection of mulridrug-resistant Salmonella from milk and meat in Bangladish. Bangl. J. Vet. Med., 16(1): 115-120.

25. Igbinosa A, E. O, Beshiru E. 0. (2017) Isolation and characterization of antibiotic suseptibility profile of Salmonella species isolated from abattoir and environment. J. Sci., 19(2): 389-397.

26. Wabeto W, Abraham $Y$ and Anjulo A (2017) Detection and identification of antimicrobial-resistant Salmonella in raw beef at Wolaita Sodo municipal abattoir, Southern Ethiopia. J. Heal. Popul. Nutr., 36(52): $1-7$.

27. Cetin E, Temelli S and Eyigor A (2020) Non-typhoid Salmonella prevalence, serovar distribution and antimicrobial-resistance in slaughter sheep, Turkey. Food Sci. Anim. Resour., 40 (1): 21-33. 
28. Garedew L, Wondafrash N and Feleke A (2016) Identification of drug-resistant Salmonella from food handlers at the University of Gondar, Ethiopia. BMC Res. Notes., 7(545): 1-9.

29. Ejo M, Garedew L, Alebachew Z and Worku W (2016) Prevalence and antimicrobia-resistance of Salmonella isolated animal-origin food items in Gondar, Ethiopia. Biomed Res. Int., 10(10): 1-8.

30. Cetin E, Temelli S and Eyigor A (2020) Non-typhoid Salmonella prevalence, serovar distribution and antimicrobial-resistance in slaughter sheep, Turkey. Food Sci. Anim. Resour., 40 (1): 21-33.

31. Gelaw A. K, Nthaba P and Matle I (2018) Detection of Salmonella from animal sources in South Africa between 2007 and 2014. J. S. Afr. Vet. Assoc., 89(0): 1-10.

32. Igbinosa A, E. $O$ and Beshiru E. 0. (2017) Isolation and characterization of antibiotic suseptibility profile of Salmonella species isolated from abattoir and environment. J. Sci., 19(2): 389-397.

33. Bonardi S, Bruini I, Magnani R, Cannistrà N and Brindani F (2017) Low prevalence of Salmonella enterica in dairy cattle at slaughter in Northern Italy. Ital. J. Food Saf., 6(6172): 1-4.

34. Vinueza-Burgos C, Cevallos M, Ron-Garrido L, Bertrand S and De Zutter L (2016) Prevalence and diversity of Salmonella serotypes in Ecuadorian broilers at slaughter age. PLoS One., 11(7): 1-12.

\section{Figures}

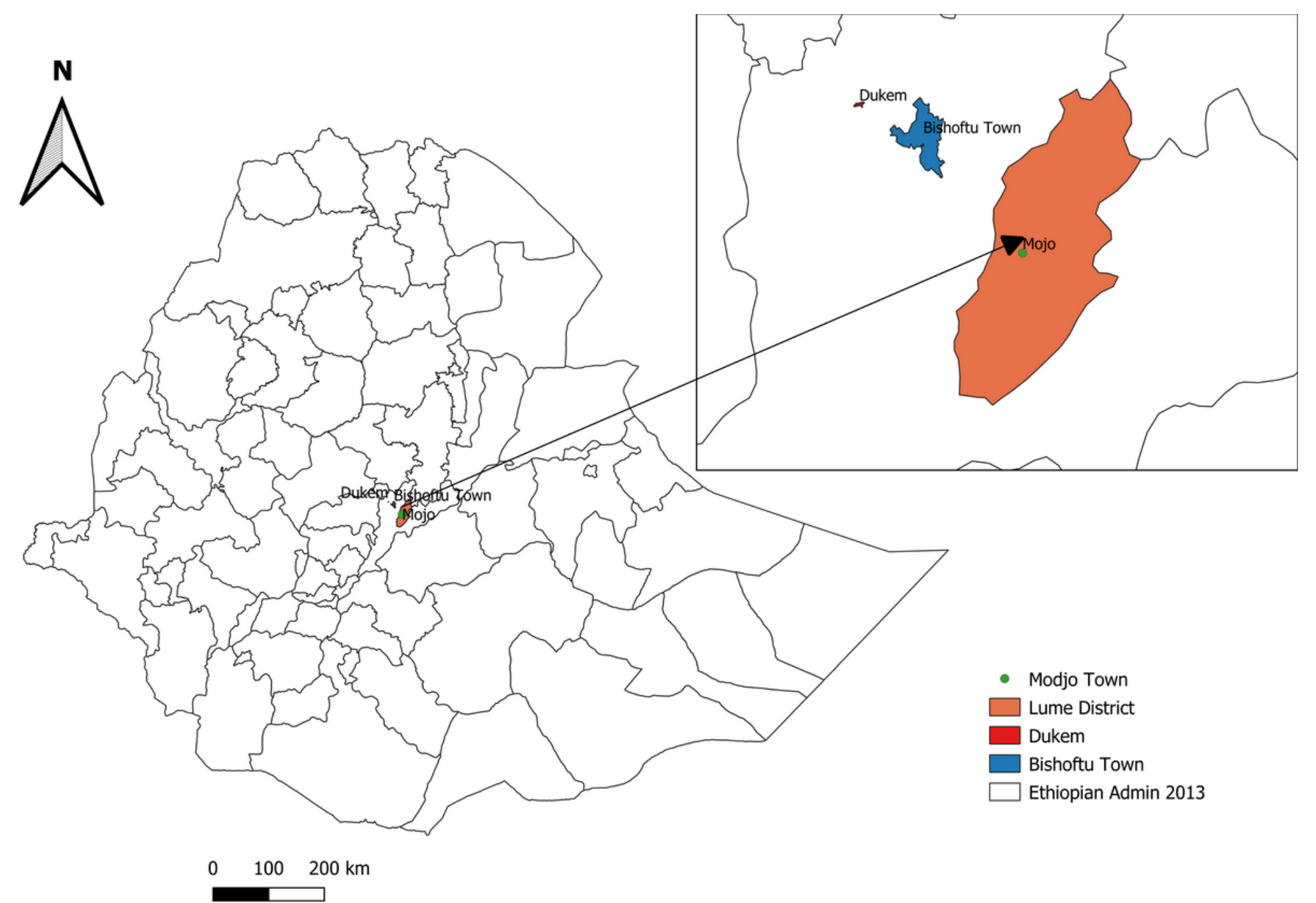


Figure 1

Geographical location of the study areas

\section{PCR result by sample type and their percentage}

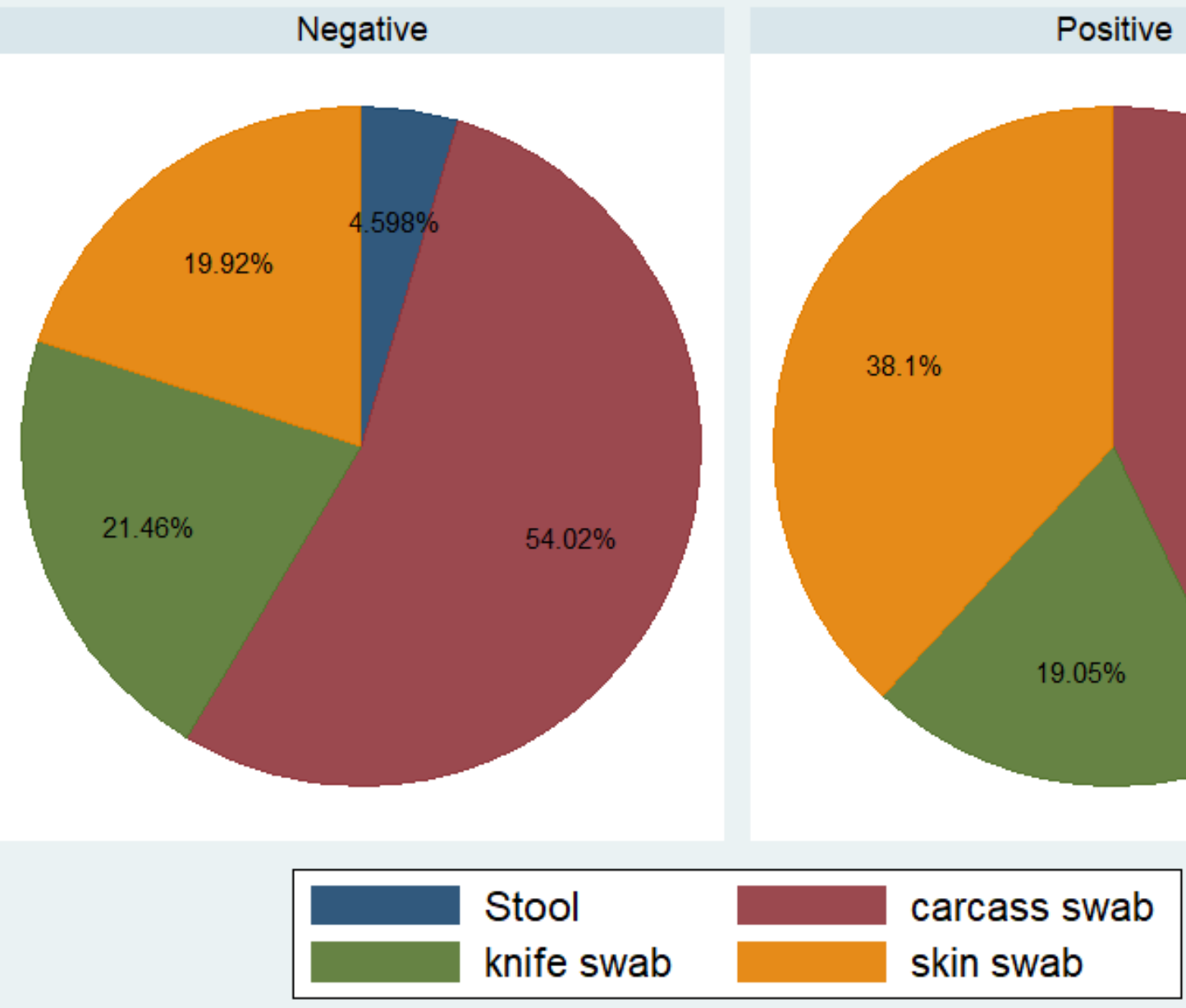

Figure 2

PCR result by pi-chart 


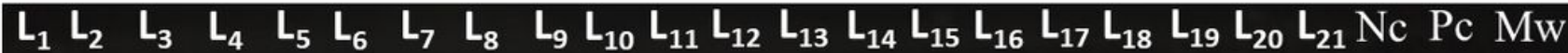

\section{Figure 3}

Agarose gel electrophoresis of the 21 Salmonella isolates confirmed by PCR test. Mw $=$ Molecular weight marker: (Kb plus DNA ladder): Lane 1-21 positive samples for Salmonella NC= negative control, $\mathrm{PC}=$ positive control (S. Typhimurium: ATCC 14028) Agarose gel electrophoresis of Salmonella PCR products at $496 \mathrm{bp}$ (16SrRNA gene) amplification of target region of histidine transport operon. 